\title{
The effect of UV radiation on cinnamate/layered double hydroxide (LDH) composites
}

\author{
Yoshikazu KAMESHIMA, ${ }^{*, *, \dagger}$ Aya NAKADA, ${ }^{* *}$ Toshihiro ISOBE, ${ }^{* *}$ \\ Akira NAKAJIMA** and Kiyoshi OKADA** \\ *Department of Material and Energy Science, Graduate School of Environmental and Life Science, Okayama University, \\ 3-1-1 Tsushima-naka, Kita-ku, Okayama 700-8530, Japan \\ ** Department of Metallurgy and Ceramic Science, Graduate School of Science and Engineering, Tokyo Institute of Technology, \\ 2-12-1 O-okayama, Meguro-ku, Tokyo 152-8552, Japan
}

\begin{abstract}
Cinnamate/layered double hydroxide (LDH) composites were prepared by a reconstruction method using sodium cinnamate solution. The cinnamate solution of $100 \mathrm{mM}$ was the most remarkable condition to obtain high cinnamate content of the cinnamate/LDH composite. The composite included about 30 mass \% of cinnamate was prepared using the $\mathrm{LDH}$ with $\mathrm{Mg} /$ $\mathrm{Al}=2$. In this composite, the new interlayer observed in XRD at $2 \theta=4.5^{\circ}$ formed a bilayer configuration of cinnamate. This composite showed excellent UV absorbability in UV-B region. Although the interlayer cinnamate changed into a dimer structure after UV radiation, the original UV absorbability was maintained in the composite.
\end{abstract}

(O2013 The Ceramic Society of Japan. All rights reserved.

Key-words : Layered double hydroxide, Cinnamic acid, UV radiation, Photodimerization

[Received October 1, 2012; Accepted November 12, 2012]

\section{Introduction}

Layered double hydroxides (LDHs) are represented by the chemical formula $\mathrm{M}^{2+}{ }_{1-x} \mathrm{M}^{3+}{ }_{x}(\mathrm{OH})_{2} \mathrm{~A}^{\mathrm{n}-}{ }_{x / \mathrm{n}} \cdot \mathrm{mH}_{2} \mathrm{O}$ and are composed of octahedral $\mathrm{M}^{2+}(\mathrm{OH})_{6}$ brucite-like layers, which are positively charged by the partial substitution of $\mathrm{M}^{3+}$ for $\mathrm{M}^{2+}$, and anions are intercalated into the interlayer to achieve charge neutrality. ${ }^{1)}$ A large number of LDHs have been synthesized due to the wide variety of combinations of cations and anions possible. Since LDHs are anion-exchangers, various anions such as metal complex ions, ${ }^{2), 3)}$ phosphate ions, ${ }^{4)}$ dodecyl sulfate ions, ${ }^{5)}$ various harmful oxyanions ${ }^{6), 7)}$ have been intercalated between their layers by ion-exchange. Various organic ions and molecules as well as inorganic ions can be intercalated into the layers using ion exchange and reconstruction methods such as alkylsulfate, ${ }^{8)}$ porphyrin, ${ }^{9)}$ phthalocyanine, ${ }^{9)}$ stearic acid, ${ }^{10)}$ oleic acid, ${ }^{11-13)}$ amino acids, ${ }^{14)}$ peptides, ${ }^{15)}{ }^{\text {DNAs }}{ }^{16)}$ and so on. Since organic ions and molecules mentioned above are much larger than inorganic ions, such an intercalation is preferably performed generally by reconstruction than ion exchange method.

Photoisomerization is most attractive molecular behaviors, in which structural change is caused by photoexcitation. Both reversible and irreversible photoisomerization reactions exist. Recently, the research of the hybrid of a photoisomerizable molecules and a layered inorganic material has received considerable attentions. Azobenzene is well known as one of the photoisomerization molecule. Ogawa et al. reported that azobenzene intercalated to magadilite and its interlayer distance was reversibly controlled by UV and visible light radiation. ${ }^{17)}$ On the other hand, cinnamic acid has irreversible photoisomerization from trans type to cis type. Cinnamic acid is also known as aroma of cinnamon and shows relatively high thermal resistance among

\footnotetext{
Corresponding author: Y. Kameshima; E-mail: ykameshi@cc. okayama-u.ac.jp
}

organic materials, ${ }^{18)}$ and has absorption in the UV-B region. Additionally, cinnamic acid has a unique property. UV irradiation of the cinnamic acid cast film resulted in a highly selective formation of a syn-Head-to-Head (syn-HH) dimer. ${ }^{19}$ Same phenomenon was observed in the suspension of hydrotalcite clay with cinnamic acid. ${ }^{20), 21)}$ Recently, cinnamic acid was intercalated into $\mathrm{Zn}-\mathrm{Al} \mathrm{LDH}$ by coprecipitation and the obtained cinnamic acid/LDH showed UV absorption ability. ${ }^{22)}$ However, there is no report on the change of interlayer cinnamic acid after UV irradiation.

In this work, cinnamate/LDH composites were prepared by reconstruction method using $\mathrm{Mg}-\mathrm{Al}-\mathrm{CO}_{3}$ type $\mathrm{LDHs}$ with $\mathrm{Mg} / \mathrm{Al}$ ratios ranging from 2 to 4 synthesized by coprecipitation. The intercalation behavior of cinnamate in the composites was investigated as a function of the $\mathrm{Mg} / \mathrm{Al}$ ratios and the preparing conditions. The change in the composites by UV radiation was also investigated, with a view to a UV absorbent.

\section{Experimental}

\subsection{Samples}

The starting materials were reagent grade magnesium nitrate hexahydrate $\left[\mathrm{MNH} ; \mathrm{Mg}\left(\mathrm{NO}_{3}\right)_{2} \cdot 6 \mathrm{H}_{2} \mathrm{O}\right]$, aluminum nitrate nonahydrate [ANN; $\left.\mathrm{Al}\left(\mathrm{NO}_{3}\right)_{3} \cdot 9 \mathrm{H}_{2} \mathrm{O}\right]$, sodium carbonate $\left(\mathrm{Na}_{2} \mathrm{CO}_{3}\right)$, sodium hydroxide $(\mathrm{NaOH})$, and ethanol. These chemicals were obtained from Wako Pure Chemicals. And cinnamic acid (CA; 3-phenyl-2-propeoic acid) was obtained from Kanto Chemicals. All these chemicals used without any purification.

Since CA only dissolved in organic solvent, sodium cinnamate (SC) synthesized used for a cinnamate source in this work. The SC precipitation was obtained by mixing an ethanol solution dissolved CA $(70 \mathrm{mmol}, 500 \mathrm{~mL})$ with a solution dissolved sodium hydroxide $(75 \mathrm{mmol}, 75 \mathrm{ml})$. After aging for $1 \mathrm{~h}$, the precipitate was separated by filtration and washed various times with ethanol. The resulting precipitate was dried at $60^{\circ} \mathrm{C}$ overnight in an oven. 
Cinnamate/LDH composite was prepared by reconstruction method. $\mathrm{Mg}-\mathrm{Al}-\mathrm{CO}_{3} \mathrm{LDH}$ was synthesized by coprecipitation method first as the host material. $\mathrm{MNH}$ and ANN were dissolved in $150 \mathrm{~mL}$ of deionized water with a total concentration of $\mathrm{Mg}^{2+}+\mathrm{Al}^{3+}=0.28 \mathrm{M}$. This solution was added to a solution $(150 \mathrm{~mL})$ dissolving $\mathrm{NaOH}(0.5 \mathrm{M})$ and $\mathrm{Na}_{2} \mathrm{CO}_{3}$, and then a precipitate was obtained. The selected molar ratios were $\mathrm{MNH}$ : $\mathrm{ANN}: \mathrm{Na}_{2} \mathrm{CO}_{3}=x: 1: 5$, where $x=2,3$, or 4 . The precipitate was mildly stirred at room temperature for $24 \mathrm{~h}$. After that, it was separated by centrifugation, washed three times with distilled water and dried at $80^{\circ} \mathrm{C}$ overnight in an oven. The synthesized $\mathrm{LDH}(0.2 \mathrm{~g})$ was first heated at $500^{\circ} \mathrm{C}$ for $12 \mathrm{~h}$ to obtain thermally decomposed LDH. This was added to solutions $(100 \mathrm{~mL})$ dissolving different concentrations of SC $(1,10,100$ and 500 $\mathrm{mM}$ ) and reacted with stirring for $24 \mathrm{~h}$ at room temperature under $\mathrm{N}_{2}$ bubbling. After this, the precipitate was separated by centrifugation and washed three times with deionized water. The resulting precipitate was dried at $60^{\circ} \mathrm{C}$ overnight in an oven.

\subsection{Characterization}

The crystalline phase was evaluated using X-ray diffractometer (XRD; XRD-6100, Shimazu Corp.) operated at $40 \mathrm{kV}$ and $30 \mathrm{~mA}$ of monochromatic $\mathrm{Cu} K \alpha$ radiation. The infrared spectra of the samples were recorded on a Fourier transform infrared spectrometer (FT-IR; FTIR-8600PC, Shimazu Corp.). Chemical compositions of the samples were analyzed for $\mathrm{Mg}^{2+}$ and $\mathrm{Al}^{3+}$ using ICP analysis (ICP-OES; iCAP6000; Thermo Electron Corp.). The contents of carbon in the composites were analyzed on a $\mathrm{CHN}$ analyzer (CHN; Corder MT-6, Yanaco Anal. Ind. Corp.) using antipyrine for the standard. Using a UV-Vis-NIR scanning spectrometer (V-630; JASCO Inc.), UV-Vis transmittance spectra were evaluated. Powder sample of $10 \mathrm{mg}$ was dispersed in $4 \mathrm{~mL}$ ethanol using a quartz cell.

\subsection{UV radiation test}

UV radiation was conducted using a UV illuminator (LA410UV-1; Hayashi Watch Works Co.) equipped with a $\mathrm{Hg}-\mathrm{Xe}$ lamp (MX4010). The illumination intensity at the sample surface was $10 \mathrm{~mW} / \mathrm{cm}^{2}$ and $150 \mathrm{~mW} / \mathrm{cm}^{2}$ at $\lambda=365 \mathrm{~nm}$. The illumination time ranged from $1 \mathrm{~h}$ to 7 days. After UV illumination, the UV radiated sample was characterized via XRD, FTIR, CHN, XPS and UV-Vis measurements.

\section{Results and discussion}

\subsection{Cinnamate/LDH composites}

In previous work, the starting $\mathrm{Mg}-\mathrm{Al} \mathrm{LDH}$ with $\mathrm{Mg} / \mathrm{Al}=3$ showed high organic content for preparing a sodium oleate/ $\mathrm{LDH}^{13)}$ and an indomethacin/LDH. ${ }^{23}$ ) Thus, the relationship between the compositing behavior and a concentration of SC solution was investigated using the $\mathrm{LDH}$ with $\mathrm{Mg} / \mathrm{Al}=3$, at first. SC concentration, cinnamate content in the composites, and estimated ratio against the anion exchange capacitance (AEC) of starting LDH were listed in Table 1. Since the amount of cinnamate in the $1 \mathrm{mM}$ sample was only 8.0 mass \% of the sample, all the cinnamate is thought to be taken into the sample. When the concentration of SC in the solution is higher than $6.7 \mathrm{mM}$, the amount of cinnamate is enough for the stoichiometric intercalation of the $\mathrm{LDH}$ with $\mathrm{Mg} / \mathrm{Al}=3$. The content of cinnamate in the $10 \mathrm{mM}$ sample was about 21 mass $\%$ and this value corresponds to about $54 \%$ of the stoichiometric amount. In the 100 and $500 \mathrm{mM}$ samples, the saturated content of cinnamate was about 26 mass $\%$ and this value corresponds to about $67 \%$ of the stoichiometric amount. From the above results, the cinnamate
Table 1. The cinnamate contents and introduced ratio against anion exchange capacity (AEC) of the composites prepared using LDH with $\mathrm{Mg} / \mathrm{Al}=3$

\begin{tabular}{ccc}
\hline $\begin{array}{c}\text { SC concentration } \\
(\mathrm{mM})\end{array}$ & $\begin{array}{c}\text { Cinnamate content } \\
(\text { mass \%) }\end{array}$ & $\begin{array}{c}\text { Ion exchange ratio } \\
(\%)\end{array}$ \\
\hline 1 & 8.0 & 20.8 \\
140 & 20.9 & 54.4 \\
100 & 25.6 & 66.7 \\
500 & 26.0 & 67.7 \\
\hline
\end{tabular}

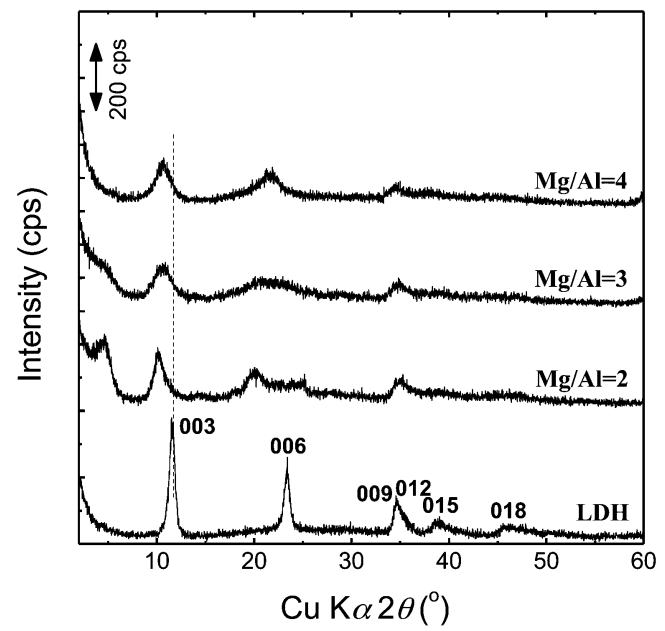

Fig. 1. XRD patterns of the synthesized $\mathrm{LDH}(\mathrm{Mg} / \mathrm{Al}=2)$ and the composites prepared by a reconstruction method using LDHs with $\mathrm{Mg} / \mathrm{Al}$ ratios ranging from 2 to 4 .

solution of $100 \mathrm{mM}$ is thought to be most remarkable condition to obtain high cinnamate content of the cinnamate/LDH composite.

The XRD patterns of the composites obtained using the LDHs with $\mathrm{Mg} / \mathrm{Al}$ ratios ranging from 2 to 4 are shown in Fig. 1. The concentration of SC solution used was $100 \mathrm{mM}$. The $00 l$ basal reflections of the synthesized cinnamate/LDH samples were slightly shifted to lower angle side with broadening of the reflections, thus, the obtained basal space of 003 reflections were $0.88 \mathrm{~nm}$ and larger than $0.76 \mathrm{~nm}$ of $\mathrm{Mg} / \mathrm{Al}=2 \mathrm{LDH}$ peak. They also show a tendency to weaken with increasing $\mathrm{Mg} / \mathrm{Al}$ ratio. New reflection is observed in the $\mathrm{Mg} / \mathrm{Al}=2$ and $\mathrm{Mg} / \mathrm{Al}=3$ sample at $2 \theta=4-5^{\circ}$. Since this peak is not observed in the original $\mathrm{LDH}$ and $\mathrm{SC}$, this is attributed to the composites. The basal space of $1.96 \mathrm{~nm}\left(2 \theta=4.5^{\circ}\right.$, in the case of $\left.\mathrm{Mg} / \mathrm{Al}=2\right)$ is considered as the sum of host layer thick of $0.48 \mathrm{~nm}$ and interlayer distance of $1.48 \mathrm{~nm}$. Since this interlayer distance is larger than the size of cinnamate ion $(0.90 \mathrm{~nm})$, the new interlayer is considered to consist by a bilayer structure of cinnamate. The bilayer of cinnamates is maintained by a hydrophobic interaction of aromatic rings. By contrast, the basal space of $0.88 \mathrm{~nm}$ is considered as a lying cinnamate intercalated in a monolayer structure. The schematic illustrators of cinnamate/LDH composite $(\mathrm{Mg} / \mathrm{Al}=2$ sample) are shown in Fig. 2. Molecular size of cinnamate is estimated using CA structure as $0.90 \mathrm{~nm}$ in length, $0.43 \mathrm{~nm}$ in width, and $0.30 \mathrm{~nm}$ in thickness. Although the estimated interlayer distance of $1.48 \mathrm{~nm}$ was shorter than the double length of cinnamate (about $1.80 \mathrm{~nm}$ ), the bilayer of cinnamate has slightly overlapped aromatic ring as Fig. 2(a) or has a gradient of about $55^{\circ}$. 
(a)

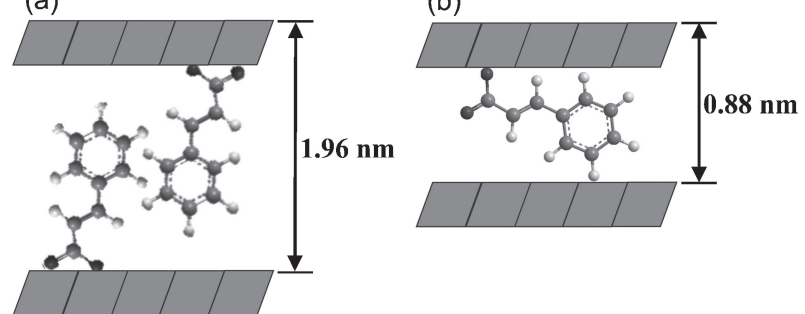

Fig. 2. Schematic illustrators of cinnamate/LDH composites. (a) bilayer model and (b) monolayer model.

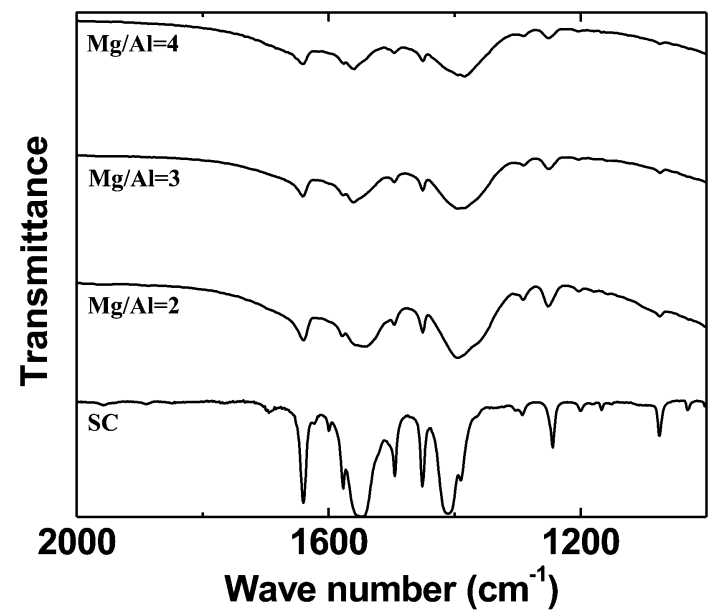

Fig. 3. FTIR spectra of the synthesized LDH $(\mathrm{Mg} / \mathrm{Al}=2)$ and the composites prepared by a reconstruction method using LDHs with $\mathrm{Mg} / \mathrm{Al}$ ratios ranging from 2 to 4 .

The cinnamate contents of the composites prepared using the LDHs with $\mathrm{Mg} / \mathrm{Al}=2,3$ and 4 were 31,26 and 21 mass \%, respectively. The values correspond to about 68,68 and $62 \%$ of the stoichiometric amount of cinnamate in the interlayer, respectively.

FTIR spectra of the composites obtained using the LDHs with $\mathrm{Mg} / \mathrm{Al}$ ratios ranging from 2 to 4 are shown in Fig. 3 with the synthesized SC. The typical absorption bands of SC were observed in SC spectrum as follows: a symmetric stretching vibration of $-\mathrm{COO}^{-}$group at $1410 \mathrm{~cm}^{-1}$, an asymmetric stretching vibration of $-\mathrm{COO}^{-}$group at $1550 \mathrm{~cm}^{-1}$, and a stretching vibration of $\mathrm{C}=\mathrm{C}$ group at $1640 \mathrm{~cm}^{-1}$. These three peaks were also observed in the composites. The peak intensity increased with the increasing of cinnamate content in the composite. Although the broad absorption peak was observed at $1300-1430 \mathrm{~cm}^{-1}$, this is considered as overlapping of $-\mathrm{COO}^{-}$ group at $1410 \mathrm{~cm}^{-1}$ and $\mathrm{CO}_{3}{ }^{2-}$ ion at $1375 \mathrm{~cm}^{-1}$. Therefore, small amount of carbonate ion exists in the obtained composite.

In general, ultra violet (UV) is separated into 3 regions; UV-A at $320-400 \mathrm{~nm}, \mathrm{UV}-\mathrm{B}$ at $280-320 \mathrm{~nm}$, and UV-C at $\sim 280 \mathrm{~nm}$. The UV-C is usually absorbed by ozonosphere and does not reach surface of the earth. Therefore, it is important for human health to block UV-B. UV-Vis transmittance spectra of starting $\mathrm{LDH}(\mathrm{Mg} / \mathrm{Al}=2), \mathrm{SC}$ and the composite of $\mathrm{Mg} / \mathrm{Al}=2$ sample are shown in Fig. 4. LDH has no absorption in the region of 200$600 \mathrm{~nm}$. SC showed two absorption bands around $200 \mathrm{~nm}$ and $240-320 \mathrm{~nm}$. The later absorption band is good agreed with the UV-B region. The cinnamate/LDH composite showed almost same profile of SC. In this work, the sample used for UV-Vis measurement was only $10 \mathrm{mg}$ that was dispersed in ethanol.

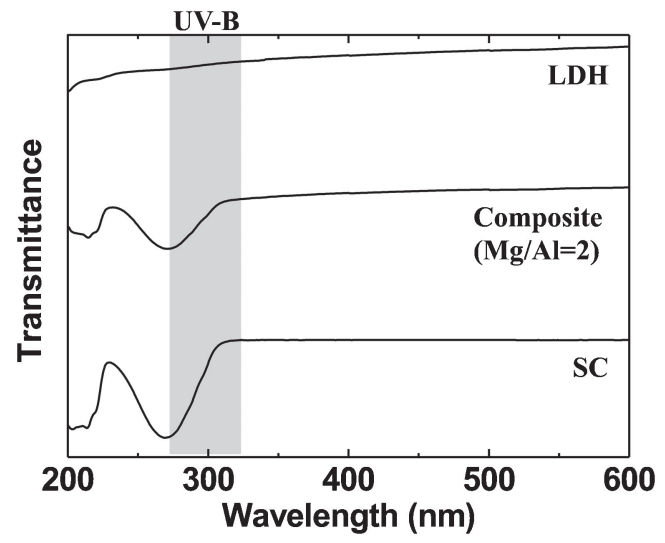

Fig. 4. UV-Vis absorbance spectra of the synthesized LDH (Mg/ $\mathrm{Al}=2$ ), $\mathrm{SC}$ and the composite prepared using $100 \mathrm{mM}$ SC solution.

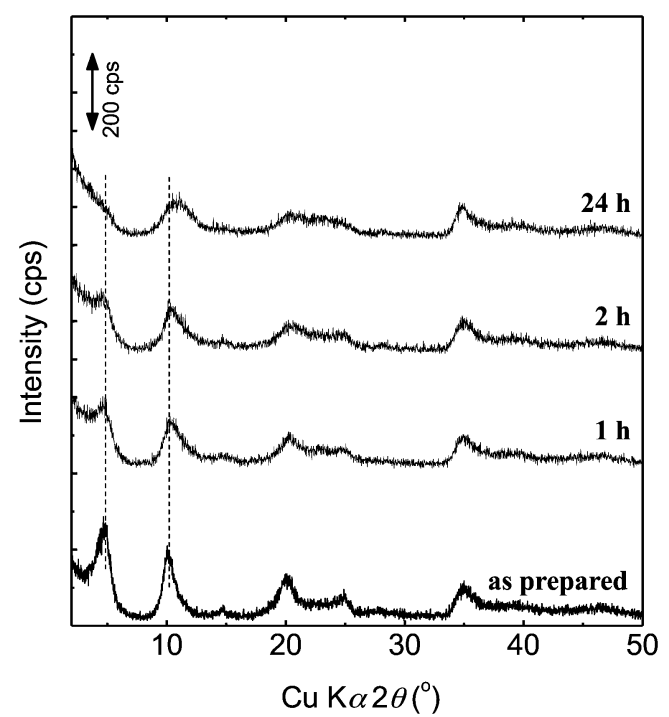

Fig. 5. XRD patterns of the composite of $\mathrm{Mg} / \mathrm{Al}=2$ sample with various UV radiation time.

Therefore, this composite showed excellent UV absorbability compared with the previous report. ${ }^{22)}$

\subsection{The effect of UV radiation}

The effect of UV radiation was investigated about the cinnamate/LDH composite prepared by reconstruction of the $\mathrm{LDH}$ of $\mathrm{Mg} / \mathrm{Al}=2$ using $\mathrm{SC}$ solution with $100 \mathrm{mM}$. Figure 5 depicts the XRD patterns change by UV radiation with intensity of $10 \mathrm{~mW} / \mathrm{cm}^{2}$. The peak at $2 \theta=4.5^{\circ}$ assigned as a bilayer of cinnamate decreased corresponding with increasing of radiation time. After $24 \mathrm{~h}$ radiation, the bilayer peak disappeared. Additionally, the peak at $2 \theta=10^{\circ}$ assigned as a monolayer of cinnamate shifted higher angle and slightly broadened. Since the peak of LDH host at $2 \theta=35^{\circ}$ did not changed, these changes suggested that the interlayer cinnamate has changed. No change was observed in FTIR spectra of these UV radiated sample because of weak and broadening transmittance spectra of as prepared composite (Fig. 3). Consequently, the UV radiation intensity has been raised from 10 to $150 \mathrm{~mW} / \mathrm{cm}^{2}$ by the investigation after this.

Figure 6 shows the FTIR spectra of the as-prepared cinnamate/LDH composite, the composite after UV radiation for $1 \mathrm{~h}$ with $150 \mathrm{~mW} / \mathrm{cm}^{2}, \mathrm{SC}, \mathrm{SC}$ after UV radiation for $24 \mathrm{~h}$ with 


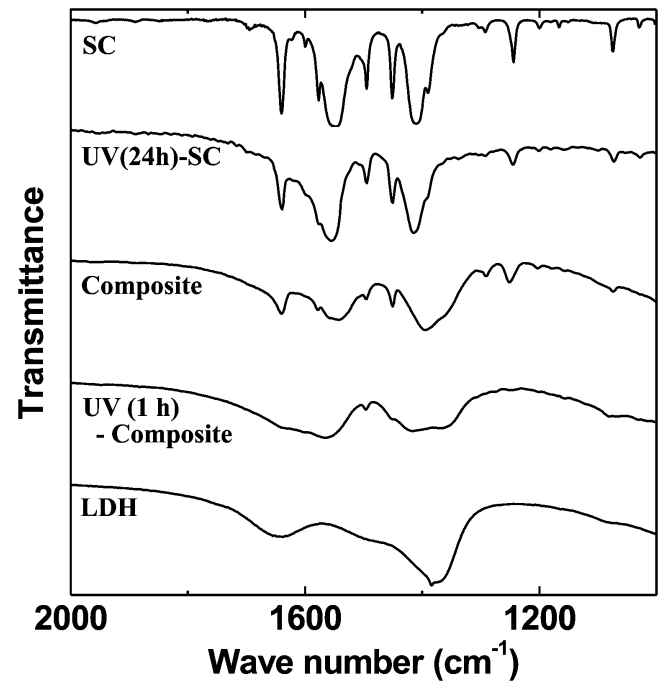

Fig. 6. FTIR spectra of the composite of the cinnamate/LDH composite, the composite after UV radiation $\left(150 \mathrm{~mW} / \mathrm{cm}^{2}, 1 \mathrm{~h}\right), \mathrm{SC}$, $\mathrm{SC}$ after UV radiation $\left(150 \mathrm{~mW} / \mathrm{cm}^{2}, 24 \mathrm{~h}\right)$ and starting $\mathrm{LDH}(\mathrm{Mg} /$ $\mathrm{Al}=2)$.

$150 \mathrm{~mW} / \mathrm{cm}^{2}$ and starting $\mathrm{LDH}(\mathrm{Mg} / \mathrm{Al}=2)$. After UV radiation, all peaks assigned as cinnamate became weaker. Carbon content of the UV radiation sample was measured by $\mathrm{CHN}$ and XPS. The carbon content by CHN analysis has not changed before and after UV radiation (from 22.7 to 23.3 mass \%). The surface carbon amount has not also changed before and after UV radiation (from 6.64 to 6.87 in atomic ratio of $\mathrm{C} / \mathrm{Al}$ ). When we observed the FTIR spectrum in detail, typical peaks assigned as cinnamate at 1410,1550 , and $1640 \mathrm{~cm}^{-1}$ have slightly shifted to high wavenumber side and also broadened. Similar change was observed in photodimerization and thermal dimerization of CA in Langmuir-Blodgett (LB) films on a silver substrate. ${ }^{24)}$ In this report, all the IR peaks in the $1760-1560 \mathrm{~cm}^{-1}$ have broadened according to the UV radiation time, and a part of these peaks has shifted to the high wavenumber side. They concluded that these changes were due to the dimerization of CA. On the other hand, absorption peaks of SC slightly broadened after UV radiation for $24 \mathrm{~h}$ with $150 \mathrm{~mW} / \mathrm{cm}^{2}$. The same absorption spectrum was also obtained after heat treatment of SC at $120^{\circ} \mathrm{C}$ for $12 \mathrm{~h}$. These results support that the photodimerization of cinnamate by UV radiation has occurred in the cinnamate/LDH composite. Additionally, Takagi et al. reported that the photodimerization of CA occurred on the surface of hydrotalcite in the suspension. ${ }^{20)}$ They also reported that the majority of the dimerization state was a syn-Head-to-Head (syn-HH) type (parallel type). Compared with these reports, the same photodimerization of cinnamate occurred in the cinnamate/LDH composite prepared by reconstruction using SC solutions. This is a first report of photodimerization of cinnamate occurred in the powder sample.

Figure 7 depicts the UV-Vis spectra change by UV radiation with intensity of $150 \mathrm{~mW} / \mathrm{cm}^{2}$. Although a strong UV illumination was radiated to the composite, the absorption peak of UV-B region was observed. From the FTIR results, the cinnamate changed to the syn-HH type dimer after 1 day UV radiation. Since the composite including syn-HH type dimer of cinnamate showed the absorption of UV-B region and the cinnamate and dimer were intercalated in the layer of the LDH in this composite, it is expected that the cinnamate/LDH composite can be used as a long life UV absorbent material.

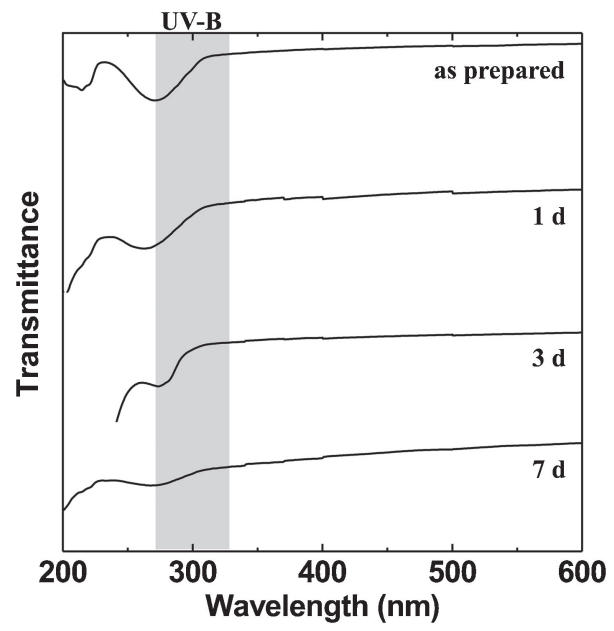

Fig. 7. UV-Vis absorbance spectra of the composite of $\mathrm{Mg} / \mathrm{Al}=2$ sample with various $U V$ radiation time.

\section{Conclusion}

In this work, the cinnamate/layered double hydroxide (LDH) composites were prepared by a reconstruction method using sodium cinnamate solution. The cinnamate/LDH composite including about 30 mass $\%$ of cinnamate was prepared by the reconstruction of thermal decomposed $\mathrm{LDH}$ with $\mathrm{Mg} / \mathrm{Al}=2$ in a sodium cinnamate solution of $100 \mathrm{mM}$. The cinnamate in the interlayers formed a bilayer configuration at high SC concentration. The composite showed a high UV absorbability in UV-B region because of the intercalated cinnamate that was an organic UV absorbent. Although the interlayer cinnamate changed after UV radiation because of a dimerization of cinnamate, the composite maintained the UV absorbability.

Acknowledgment We are grateful to Professor T. Tsurumi of Tokyo Institute of Technology for valuable support in ICP-OES analysis.

\section{References}

1) K. A. Carrado, A. Kostapapas and S. L. Suib, Solid State Ionics, 26, 77-86 (1988).

2) S. Miyata and T. Kumura, Chem. Lett., 1973, 843-848 (1973).

3) K. Okada, F. Matsushita and S. Hayashi, Clay Miner., 32, 299305 (1997).

4) P. K. Dutta and M. Puri, J. Phys. Chem., 93, 376-381 (1989).

5) Y. Sugahara, N. Yokoyama, K. Kuroda and C. Kato, Ceram. Int., 14, 163-167 (1988).

6) Y. You, G. F. Vance and H. Zhao, Appl. Clay Sci., 20, 13-25 (2001).

7) N. N. Das, J. Konar, M. K. Mohanta and S. C. Srivastava, J. Colloid Interface Sci., 270, 1-8 (2004).

8) K. Chibwe and W. Jones, J. Chem. Soc. Chem. Commun., 1989, 926-927 (1989).

9) L. Ukrainczyk, M. Chibwe, T. J. Pinnavaia and S. A. Boyd, Environ. Sci. Technol., 29, 439-445 (1995).

10) T. Kanoh, T. Shichi and K. Takagi, Chem. Lett., 1999, 117-118 (1999).

11) Z. P. Xu, P. S. Braterman, K. Yu, H. Xu, Y. Wang and C. J. Brinker, Chem. Mater., 16, 2750-2756 (2004).

12) K. Inomata and M. Ogawa, Bull. Chem. Soc. Jpn., 79, 336-342 (2006).

13) Y. Kameshima, H. Yoshizaki, A. Nakajima and K. Okada, J. Colloid Interface Sci., 298, 624-628 (2006). 
14) S. Aisawa, S. Takahashi, W. Ogasawara, Y. Uematsu and E. Narita, J. Solid State Chem., 162, 52-62 (2001).

15) H. Nakayama, N. Wada and M. Tsuhako, Int. J. Pharm., 269, 469-478 (2004).

16) J. Portier, G. Campet, N. Treuil, A. Poquet, Y. I. Kim, S. J. Kwon, S. Y. Kwak and J. H. Choy, J. Korean Chem. Soc., 42, 487-499 (1998).

17) M. Ogawa, J. Mater. Chem., 12, 3304-3307 (2002).

18) W. G. Kim, J. Appl. Polym. Sci., 107, 3615-3624 (2008).

19) T. Nakamura, K. Takagi and Y. Sawaki, Bull. Chem. Soc. Jpn., 71, 909-914 (1998).
20) K. Takagi, T. Shichi, H. Usami and Y. Sawaki, J. Am. Chem. Soc., 115, 4339-4344 (1993).

21) T. Shichi, T. Takagi and Y. Sawaki, Chem. Lett., 25, 781-782 (1996).

22) W. Sun, Q. He and Y. Luo, Mater. Lett., 61, 1881-1884 (2007).

23) Y. Kameshima, H. Obata, A. Nakajima and K. Okada, Preparation of indomethacin/layered double hydroxide (LDH) composites and its release behavior of indomethacin, Abstracts of 51th Clay Science Society of Japan (2007) pp. 116-117.

24) M. Yamamoto, N. Furuyama and K. Itoh, J. Phys. Chem., 100, 18483-18490 (1996). 